\title{
Educação on-line e os impactos no sistema de ensino durante a pandemia da COVID-19
}

\author{
Online education and impacts on the education system during the COVID-19 pandemic \\ Educación en línea e impactos en el sistema educativo durante la pandemia de COVID-19
}

\begin{abstract}
Resumo
O artigo tem como objetivo destacar que durante a pandemia da COVID-19 as metodologias ativas foram os meios proporcionados aos estudantes pelas políticas públicas educacionais de forma a leva-los a serem protagonistas de seu processo de ensino e aprendizagem, por meio de alternativas para a consolidação de seu aprendizado sem precisar da presença física do professor. Diante da nova realidade da educação brasileira, os professores tiveram que se adaptar as novas tecnologias de forma a sancionar as demandas impostas pelas instituições educacionais em levar aos alunos uma educação de qualidade, sem que os mesmos perdessem seus rendimentos escolares impostos pela nova realidade educacional. Em tempos antigos a educação a distância não era vista como uma educação de qualidade, e de repente o mundo precisou da educação on-line para levar o conhecimento a milhares de crianças e jovens em período da pandemia. Instituições educacionais tiveram que se adequar à nova realidade tecnológica para suprir a ausência de aulas presenciais, sem perder a qualidade de ensino. Vale ressaltar que toda nova proposta para evolução da educação requer estudos e treinamentos dos envolvido no processo de ensino e aprendizagem, onde as intuições de ensino promovam meios para que os professores e alunos consigam uma formação para manuseio das novas tecnologias a favor da aprendizagem. Diante do explanado, a educação on-line veio para suprir as demandas dos sistemas de ensino de forma que os estudantes precisam ser os protagonistas na construção de sua aprendizagem tendo o computador e os celulares seus aliados como principais ferramenta de estudo.
\end{abstract}

Palavras-chave: Educação; Ensino remoto; COVID-19; Aprendizagem.

\begin{abstract}
The article aims to highlight that during the COVID-19 pandemic, active methodologies were the means provided to students by educational public policies in order to lead them to be protagonists of their teaching and learning process, through alternatives for consolidation of your learning without needing the physical presence of the teacher. Faced with the new reality of Brazilian education, teachers had to adapt to new technologies in order to sanction the demands imposed by educational institutions to provide students with quality education, without losing their school earnings imposed by the new educational reality. In ancient times, distance education was not seen as a quality education, and suddenly the world needed online education to bring knowledge to thousands of children and young people during the pandemic period. Educational institutions had to adapt to the new technological reality to make up for the absence of in-person classes, without losing the quality of teaching. It is noteworthy that any new proposal for the evolution of education requires studies and training of those involved in the teaching and learning process, where teaching intuitions promote ways for teachers and students to obtain training to handle new technologies in favor of learning. Given the above, online education came to meet the demands of education systems so that students need to be the protagonists in the construction of their learning with the computer and cell phones as their main study tools.
\end{abstract}

Keywords: Education; Remote teaching; COVID-19; Learning. 


\section{Resumen}

El artículo tiene como objetivo resaltar que durante la pandemia COVID-19, las metodologías activas fueron los medios que las políticas públicas educativas brindaron a los estudiantes para llevarlos a ser protagonistas de su proceso de enseñanza y aprendizaje, a través de alternativas para la consolidación de sus aprendizajes sin necesidad de la presencia física del maestro. Ante la nueva realidad de la educación brasileña, los docentes tuvieron que adaptarse a las nuevas tecnologías para sancionar las demandas impuestas por las instituciones educativas de brindar a los estudiantes una educación de calidad, sin perder sus ingresos escolares impuestos por la nueva realidad educativa. En la antigüedad, la educación a distancia no se consideraba una educación de calidad y, de repente, el mundo necesitaba educación en línea para llevar el conocimiento a miles de niños y jóvenes durante el período de la pandemia. Las instituciones educativas tuvieron que adaptarse a la nueva realidad tecnológica para suplir la ausencia de clases presenciales, sin perder la calidad de la enseñanza. Es de destacar que cualquier nueva propuesta para la evolución de la educación requiere estudios y formación de los involucrados en el proceso de enseñanza y aprendizaje, donde las intuiciones docentes promuevan formas para que docentes y estudiantes obtengan una formación para manejar las nuevas tecnologías a favor del aprendizaje. Dado lo anterior, la educación en línea llegó a satisfacer las demandas de los sistemas educativos por lo que los estudiantes deben ser los protagonistas en la construcción de su aprendizaje con la computadora y el teléfono celular como sus principales herramientas de estudio.

Palabras clave: Educación; Enseñanza remota; COVID-19; Aprendiendo.

\section{Introdução}

Para Ribeiro. R. Santos (2010), mesmo sendo uma prática não muito recente, somente na segunda metade do século XX observa-se um cuidado maior na elaboração de conceitos que realmente reflitam o significado de Educação a Distância como um processo educacional. Mas antes de se ponderar sobre esse modelo, torna-se necessário diferenciar educação e ensino, visando uma construção teórica significativa em torno da educação on-line.

Pela diferenciação feita por Landim (1997), o ensino é mais ligado às atividades de treinamento, adestramento e instrução, centrada na transmissão do conhecimento. Por outro lado, a educação é vista de uma forma mais ampla por tratarse de um processo ensino-aprendizagem, onde o aluno aprende a saber, pensar, criar, inovar, construir conhecimentos e participar ativamente de seu próprio crescimento.

Para G. Dohmem apud Nunes (1992), a Educação a Distância é uma forma sistematicamente organizada de autoestudo, onde o aluno se instrui a partir do material de estudo que lhe é apresentado, e o acompanhamento e a supervisão do sucesso do estudante são levados a cabo por um grupo de professores. Isto é possível de ser feito a distância através da aplicação de meios de comunicação capazes de vencer longas distâncias.

Por sua vez, a Educação a Distância também pode ser definida como: "uma relação professor-aluno ou ensinoaprendizagem mediada pedagogicamente e mediatizada por diversos materiais instrucionais e pela orientação tutorial, isto é válido tanto para ambientes pedagógicos tradicionais como para aqueles que usam as novas tecnologias". (Riano, 1997, p. 20). Seguindo esse paradigma conceitual, Perry e Rumble (1987, p.1 $\neg 2)$ afirmam que:

A característica básica da Educação a Distância é o estabelecimento de uma comunicação de dupla via, na medida em que professor e aluno não se encontram juntos na mesma sala requisitando, assim, meios que possibilitem a comunicação entre ambos como correspondência postal, correspondência eletrônica, telefone ou telex, rádio, "modem", videodisco controlado por computador, televisão apoiada em meios abertos de dupla comunicação, etc. Afirmam, também, que há muitas denominações utilizadas correntemente para descrever a Educação a Distância, como: estudo aberto, educação não $\neg$ tradicional, estudo externo, extensão, estudo por contrato, estudo experimental.

Bordenave (1986) prefere conceituar a Educação a Distância como uma proposta constituída através de um processo ensino-aprendizagem, atuando com estudantes de diversas idades e antecedentes no desenvolvimento de estudos em grupo ou individualmente, em casa, locais de trabalho ou em qualquer outro ambiente geograficamente distante, usando materiais 
autoinstrutivos produzidos em um centro docente, distribuídos através de diversos meios de comunicação regular com os professores do centro docente.

Em tempos antigos a educação a distância não era vista como uma educação de qualidade, e de repente o mundo precisou da educação online para levar o conhecimento a milhares de crianças e jovens em período da pandemia.

Instituições educacionais tiveram que se adequar a nova realidade tecnológica para suprir a ausência de aulas presenciais, sem perder a qualidade de ensino.

Tais conceitos proporcionam para a educação on-line uma concepção de convergência da Educação a Distância com as Tecnologias da Informação e Comunicação (TIC). Trata-se de uma metodologia onde o aluno aprende através de conteúdos disponíveis no computador ou na Internet, ou os dois simultaneamente, sendo o professor, se existir, está geograficamente distante do aluno, comunicando-se através dos meios interativos disponíveis pela Internet, podendo existir ainda, sessões presenciais.

A principal particularidade da educação on-line é a de estar situado num ambiente digitalizado, o que lhe oferece algumas características pedagógicas e comunicativas diferenciadas das demais modalidades da educação como: possibilitar a elaboração coletiva do saber para as trocas comunicativas instantâneas e ao acesso ilimitado as fontes de informação, principalmente, para relações em redes, para as lógicas não hierárquicas e não lineares ; permite uma renovação de valores e métodos educacionais que podem resolver questões tanto da educação presencial como da Educação a Distância como: maior acesso, menor custo, mais interatividade, flexibilidade e continuidade, dentre outras; disponibiliza ambientes envolventes e dinâmicos capazes de mobilizar a atenção, garantindo a comunicação em tempo real ou não, além de estimular a aprendizagem; possibilita a separação física aluno-professor, o uso de comunicação em dois sentidos suportada pela internet e o uso de uma rede computacional para apresentação ou distribuição de conteúdo educacional.

Outro fator relevante é que a educação on-line vem sendo alvo de inúmeros estudos, e na medida em que é aplicado no ensino superior, também vai sofrendo modificações em sua conceitualização. Neste sentido, a própria terminologia usada também vai mudando. Para Lencastre e Araújo (2009), o que era universalmente conhecido como ensino ou Educação a Distância é hoje conhecido como aprendizagem a distância, enfatizando a aprendizagem do estudante.

Neste sentido, a educação on-line refere a um modelo mediado por meios eletrônicos, comumente, mas erradamente, designada de E-Learning (ensino eletrônico). Da mesma forma que o ensino através de cartas evoluiu ao longo de sua história para a Educação a Distância, o ensino on-line também transcendeu limitações, chegando ao status de educação on-line. O Elearning é um modelo que cresceu durante os anos 90 com o advento da Internet, e trata do uso de tecnologias que suportam uma aprendizagem num determinado tempo e espaço bastante específico, fixo e conservador, onde a instrução predomina em sua essência.

Evidentemente, que entre os fatores para essa reconceitualização está o surgimento de novos aparatos que proporcionam altos níveis de interação e interatividade nunca antes utilizadas pela modalidade à distância. A educação on-line decorre da própria evolução pedagógica e tecnológica do E-learning, relacionada com o uso da internet e seus recursos como meios na publicação de material didático-pedagógico para realização de cursos, na comunicação entre alunos e professores e em várias possibilidades interativas capazes de proporcionar a colaboração e a cooperação na construção de conhecimentos.

Nesta concepção, a educação on-line passa a envolver não só a Internet, mas dispositivos eletrônicos capazes de armazenar ou fornecer material educativo a qualquer momento para ser usado em qualquer outro computador ou dispositivos de multimídia como o CD (Disco Compacto), DVD (Disco Digital Versátil), Pendrive e outros.

Verifica-se, que esse modelo busca não perder o foco do processo ensino-aprendizagem, e nesta perspectiva, conceitua-se pela distribuição de conhecimento cuidadosamente construído através de tecnologias. Contudo, a educação on- 
line se sustenta fielmente na prerrogativa da aprendizagem, que é uma atividade inerente a qualquer humano, podendo acontecer em qualquer lugar onde as pessoas estão disponíveis para querer aprender.

Este cuidado parece adequado para uma definição que exclui a simples comunicação por computador e ainda, a distribuição eletrônica de documentos a não ser que sejam usados num contexto de ensino-aprendizagem. Contudo, a maior particularidade da educação on-line é ser realizada em um espaço digitalizado, além de possuir algumas características midiáticas diferenciadas das demais modalidades e que será comentado posteriormente.

Um espaço digitalizado como a internet potencializa o uso de softwares baseados em gerenciadores $\mathrm{e}$ compartilhadores de arquivos voltadas para educação como os Ambientes Virtuais de Aprendizagem (AVA), que surgiram na década de 90 e até hoje constituem um importante instrumento para as mediações pedagógicas à distância. Esses programas não são condicionantes para determinar se um curso na web é educação on-line, mas sua utilização amplifica as mediações para a modalidade, visando mobilizar a atenção de seus usuários através de um processo envolvente e dinâmico, proporcionado pelos diversos meios comunicativos disponíveis no sistema.

Contudo, as dinâmicas propostas pela educação on-line mediado por AVA assemelham-se com as concepções de Cibercultura apresentadas por Lévy (1999) como: a elaboração, construção e compartilhamento coletivo do saber ocorrendo através das trocas instantâneas das comunicações peculiares desses sistemas, o acesso ilimitado as fontes da própria internet e o incentivo às relações em redes para lógicas não hierárquicas e não lineares.

Para Lencastre e Araújo (2009), o que era universalmente conhecido como ensino ou Educação a Distância é hoje conhecido como aprendizagem a distância, enfatizando a aprendizagem do estudante.

Vale ressaltar que toda nova proposta para evolução da educação requer estudos e treinamentos dos envolvido no processo de ensino e aprendizagem, onde as intuições de ensino promovam meios para que os professores e alunos consigam uma formação para manuseio das novas tecnologias a favor da aprendizagem.

Diante do explanado, a educação online veio para suprir as demandas dos sistemas de ensino de forma que os estudantes precisam ser os protagonistas na construção de sua aprendizagem tendo o computador e os celulares seus aliados como principais ferramenta de estudo.

O comodismo fez com que os professores ficassem alienados somente a livros e salas de aula no sistema de aula presencial, mas diante da nova realidade enfrentada pelos sistemas de ensino, os professores se viram pedidos em meio a tantas tecnologias disponibilizadas a favor da aprendizagem, sem possuir sabedoria para levar aos estudantes o conhecimento por meio do sistema online. As secretarias de educação tiveram que de forma imediata proporcionar formações tecnológicas a todos os envolvidos no processo de ensino e aprendizagem para que todos pudessem possuir conhecimento das plataformas digitais que seriam inseridas como suporte para realização das aulas online, onde a maior preocupação seria com os estudantes por possuírem um acesso mais fácil e mais adaptados em manusear a internet de forma mais habilidosa do que o profissionais que não tinham tanto acesso a rede virtual, sendo que o aluno por ele mesmo poderá pesquisar o tema da aula do professor a qualquer momento, não dependendo de interferências do discente, levando o professor a superar mais um desafio em promover aulas mais atraentes de forma que pudesse envolver o auno sem que ele precisasse pesquisar o conteúdo trabalhado.

Toda a equipe envolvida com o processo de ensino aprendizagem por meio do sistema on-line da escola se depararam diante de uma realidade jamais presenciada por escolas públicas, onde o ensino era fornecido somente através das transmissões de saberes de professores e alunos dentro de uma sala de aula de ensino regular, e depois da realidade enfrentada diante o período pandêmico, tiveram que se adaptar a nova realidade por meio de instalações tecnológicas e internet de boa qualidade dentro do ambiente educacional e meios para que todos os envolvidos no processo soubessem utilizar as tecnologias para suprir a necessidade de aprendizagem do estudante. 
Hoje a realidade diante ao enfrentamento do colapso que vem se transformando os sistemas de ensino devido ao contágio do vírus (Corona vírus), os órgãos governamentais em parceria $\mathrm{cm}$ as secretarias estaduais e municipais de educação buscaram metodologias por meio de aplicativos e plataformas digitais para que o ensino dos estudantes pudessem estar voltado somente para aulas online, que ficou conhecido como sistema remoto de ensino, para isso adquiriu em parceria com o Google plataformas que se transformam em sala de aula em tempo real para que os professores pudessem repassar os conteúdos de acordo com o currículo de cada modalidade de ensino.

Para que os alunos continuassem no ritmo de estudo, foi disponibilizado pelo drive escolar planilhas de monitoramento onde os professores agendavam suas aulas conforme seus horários e disponibilizavam as atividades por meio o Google sala de aula onde por meio de links gerados pelo próprio sistema Classroom os alunos acessavam as plataformas em tempo real conseguiam assistir as aulas desenvolvidas dentro de seu horário escolar. Os sistemas educacionais tiveram que buscar soluções e equipar as escolas com internet de qualidade e equipamentos tecnológicos para que o ensino pudesse chegar ao aluno de forma eficaz e proporcionar ao discente oportunidades de construir aprendizagens significativas preparando-os para o mercado de trabalho.

O ensino online requer do aluno uma maior dedicação onde na maioria das vezes precisam sanar suas dúvidas sozinhos ou pelos aplicativos de smartfones nos quais possuem grupos de sala de aula, levando o aluno um maior estudo e pesquisas online no assunto abordado em sala de aula virtual, mesmo assim o rendimento escolar de alguns alunos caíram, e foi observado o baixo índice de participação no início da introdução das tecnologias como ferramenta de ensino.

Os sistemas educacionais ficaram sobrecarregados de tantas in formações com as inserções das tecnologias como principal meio de transmissão do conhecimento, levando os professores a uma sobrecarga funcional e pessoal, demonstrando quadros depressivos, ansiedade e cansaço pelo acúmulo de trabalho e estudo para que os alunos não ficassem prejudicados devido a nova realidade dos sistemas educacionais.

\section{Metodologia}

A metodologia utilizada para a produção deste estudo foi de pesquisa bibliográfica, realizada em meio virtual, com artigos disponível e e-books em sites confiáveis, de conteúdo científico.

A pesquisa bibliográfica, ou de fontes secundárias, abrange toda bibliografia já tornada pública em relação ao tema de estudo, desde publicações avulsas, boletins, jornais, revistas, livros, pesquisas, monografias, teses, material cartográfico etc. [...] Dessa forma, a pesquisa bibliográfica não é mera repetição do que já foi dito ou escrito sobre certo assunto, mas propicia o exame de um tema sob novo enfoque ou abordagem, chegando a conclusões inovadoras (Lakatos, Marconi, 2010, p.166).

Sendo assim, foram selecionados artigos e e-books resultantes de pesquisa em meio virtual, com os descritores: Educação, Ensino remoto, COVID-19 e Aprendizagem.

Artigos que não correlacionavam os quatro descritores foram excluídos. Após a exclusão, foi feita uma leitura analítica que resultou na fundamentação teórica deste estudo, apresentada em resultados e discussões e subdividida em títulos.

As conclusões, incluindo algumas propostas e as impressões dos autores, encontram-se nas considerações finais.

\section{Resultados e Discussão}

De acordo com a abordagem de Brenand, Duarte e Kenski (2006), percebe-se que, com o avanço da ciência e da tecnologia, assim como de seus produtos e serviços correlatos, as possibilidades com que a educação pode usufruir dos recursos que facilitem a mediação interativa dos seus conteúdos de ensino, fazem parte de uma realidade que chega às salas de 
aula pelos próprios alunos. Notebooks, smartphones e demais aparelhos, como também comportamentos e conversas pautadas em discursos midiáticos, integram a escola na mesma proporção em que esta tentou, até certo tempo, ignorar o contexto comunicativo das mídias, como se fosse uma realidade paralela.

Para Moran (2002), existem três tipos de educação: a presencial, em que professores e alunos se encontram num lugar físico chamado sala de aula (ensino convencional); a semipresencial, que acontece uma parte na sala de aula física e outra parte a distância, por meio de tecnologias; e a Educação a Distância ou virtual, que pode ter ou não momentos presenciais, mas acontece fundamentalmente com professores e alunos separados fisicamente no espaço e/ou no tempo, mas podendo estar juntos através das TIC. Oliveira (2014) explica que a educação presencial ocorre no mesmo espaço físico e no mesmo momento temporal. Já na modalidade a distância, os professores podem estar 236 Comunicações Piracicaba v. 24 n. 2 p. 229-246 maio-agosto 2017 separados geograficamente e de forma temporal, mas podem estar conectados através do uso das tecnologias. "Esta modalidade de educação é efetivada através do uso intensivo de tecnologias de informação e comunicação (TIC), podendo ou não apresentar momentos presenciais" (Oliveira, 2014, p. 15)

Passarelli (2007, p. 49) define a EAD "[...] como aquela onde professor e aluno estão distantes geograficamente". Também acrescenta o conceito de midiatização no processo de aprendizagem, uma vez que a distância física entre eles necessita ser vencida por algum meio de comunicação, como mídia impressa, telefone, rádio, televisão, vídeos, computadores, CD-ROM, internet, videoconferência e outros (Passarelli, 2007, p. 49). Já Carvalho (2014) explica que a EAD desde o seu surgimento remoto como modalidade de educação é acompanhada de perto pelo desenvolvimento das TIC, adequando-se às novas velocidades e a cada modalidade disponível para o fluxo da informação. Moore e Kearsley (2007) reforçam esse conceito, evidenciando a EAD em cinco gerações em função das tecnologias vigentes em cada época. A primeira geração (1880) é marcada pelo início do ensino por correspondência por meio dos serviços postais. O surgimento e a difusão do rádio e da televisão, a partir da década de 1920, trouxeram o ensino através desses dois veículos de comunicação, possibilitando a propagação da informação em massa, caracterizando a segunda geração de EAD. Já a terceira geração (1960) é marcada por uma difusão de conhecimento de maneira organizada, com o uso de diferentes ferramentas tecnológicas da época, incluindo o telefone e o fax. A quarta geração de EAD veio com o lançamento dos satélites de comunicação, tornando viável o ensino através do áudio e da videoconferência. A quinta e última geração de EAD é marcada pela popularização do computador e da consolidação da internet a partir da década de 1990, rompendo definitivamente qualquer barreira física e atingindo uma nova dimensão.

É inegável que as inovações causadas pelo avanço das TIC na área da educação, principalmente aquelas que incorporaram a internet como suporte para a Educação a Distância (EAD), geraram uma mudança nos perfis dos seus atores, configurando novas formas de ensinar e aprender. "Ao mesmo tempo, verifica-se que o perfil dos alunos está em transformação, exigindo a revisão das práticas pedagógicas e dos professores" (Scheneider; Silva; Behar, 2013). Passarelli afirma que "[...] o mundo globalizado, caracterizado por intensos fluxos de capitais, produtos e informação passa a exigir de seus cidadãos novas competências" (Passarelli, 2007, p. 40). Esses conceitos nos trazem a outras mudanças. Se as práticas pedagógicas sofreram alteração, também surge a necessidade de modificar os docentes. Novos papéis são criados a partir das novas tecnologias digitais na Educação a Distância, surgindo a figura do tutor. A função do tutor é vista de forma diferente da do professor. Enquanto o último elabora, organiza o conteúdo e prepara o material a ser utilizado nos cursos, o primeiro desempenha um papel de mediador entre o material didático e o aluno (Espíndola; Nascimento, 2014). Tal conceito é reforçado por Fava (2014, p. 37), para quem “[...] o professor presencial é o responsável pelos conteúdos e o professor a distância, o responsável por fazer a tutoria, orientação e atendimento dos discentes”. 
Deve-se levar em conta que crianças e jovens estão, cada vez mais, conectados às tecnologias digitais, configurandose como uma geração que estabelece novas relações com o conhecimento, o que requer, portanto, que transformações aconteçam na escola (Bacich; Tanzi Neto; Trevisani, 2015).

Sendo assim, diante da análise da pesquisa , pode-se observar que os sistemas de ensino passaram por desafios em criar sistemas educacionais on-line que favorecesse o aprendizado do aluno tendo como suporte plataformas digitais e aplicativos midiáticos que suprisse a necessidade pedagógica dos conteúdos trabalhados pelos discentes, tendo o professor um facilitador e o aluno o responsável em construir sua aprendizagem de forma conectada, baseada em recursos tecnológicos e midiáticos em favor do conhecimento tecnológico/cientifico.

Diante do exposto, os professores relataram nos questionários a sobrecarga de trabalho em produzir materiais para os alunos que estavam no sistema remoto on-line e para aqueles que não possuíam acesso a internet e em cumprir com os cronogramas das aulas on-line pela plataforma Meet, e por ainda monitorar alunos por meio de planilhas digitais fornecidas pelos sistemas educacionais causando exaustão a todos os envolvidos nesse processo de ensino e aprendizagem.

O maior desafio, foi levar o conhecimento o máximo de alunos possíveis, sem deixar que perdessem o rendimento e escolar, onde perceberam por meio de relato dos alunos uma falta de interesse em buscar seu conhecimento por meio do sistema remoto de ensino.

\section{Considerações Finais}

Concluímos que o sistema on-line de ensino veio para suprir a demanda de todas as escolas devido o período pandêmico de forma a preencher as demandas da aprendizagem dos alunos por meio de plataformas e aplicativos celulares, levando o discente a construir sua aprendizagem por meio do sistema online.

Os sistemas de ensino tiveram que se equipar de forma rápida para que os alunos não tivessem perda de aprendizagem, e buscou parcerias com o Google por meio, de plataformas disponíveis a favor da aprendizagem, para que os professores conseguissem repassar aos alunos os conteúdos disponíveis no currículo escolar de cada etapa de aprendizagem, acarretando aos professores uma sobrecarga de trabalho, por terem que trabalhar em sistemas nos quais eles não possuíam domínio da inserção das novas tecnologias ativas a favor da aprendizagem.

Segundo relato de alunos, as plataformas fizeram com que eles se sentissem desmotivados no início do período pandêmico por não acreditarem que seriam capazes de construir sua aprendizagem por meio das tecnologias assistivas, tendo o professor como facilitador e não mais como mediador do processo de construção do saber, levando os alunos o não cumprimento de seus deveres enquanto aluno.

Os professores tiveram que adaptar as aulas de forma atrativa para conseguir abranger de forma mais ampla o mais quantitativo de público possível focando nas devolutivas das atividades com intuito de promover uma aprendizagem significativa para o discente em um período tão crítico e desacreditado por todos.

Sendo assim, os sistemas educacionais, promoveram meios e recursos tecnológicos de forma a auxiliar professores e alunos, para que dessa forma a aprendizagem pudesse ocorrer de forma igualitária a todos os envolvidos no processo da construção do saber.

E assim de acordo com essa realidade, onde as necessidades em relação à aprendizagem necessitam dos recursos tecnológicos, sendo uma metodologia própria e segura, no que se refere à pandemia do Covid-19, deve-se oferecer e definir políticas para a criação de programas de formação e de capacitação para todos os agentes educativos direcionados para o desenvolvimento de projetos de formação e educação digital que permitam realizar uma adequada transição para uma educação digital em rede de qualidade. 


\section{Bibliografia}

Bacich, L., Tanzi Neto, A., \& Trevisani, F. D. M. Ensino híbrido: personalização e tecnologia na educação. In: Bacich, L., Tanzi Neto, A., \& Trevisani, F. D. M. Ensino híbrido: personalização e tecnologia na educação, (1 ${ }^{\text {a }}$. ed.): Penso, 2015. Cap. 2, p. 47-65.

Brasil (2020). Ministério da Educação. Corona vírus: monitoramento nas instituições de ensino. http://portal.mec.gov.br/coronavirus

Carmo, R. O. S., \& Franco, A. P. (2019). Da docência presencial à docência online: aprendizagens de professores universitários da educação à distância. Educação em Revista, 35:1-29. http://dx.doi.org/10. 1590/0102-4698210399

Carvalho, C. A. M. D. Avaliando as ferramentas na EAD: diferentes possibilidades frente a um mundo de novas TICs. In: Coelho, F. J. F., \& Vellosos, A. Educação à distância: história, personagens e contextos, (1ª. ed.): CRV, 2014. Cap. 3, p. 43-49.

Espíndola, C. D. S. O., \& Nascimento, R. S. O professor, a disciplina e os conteúdos na EAD. In: Coelho, F. J. F.; Velloso, A. Educação à distância história personagens e contexto, (1 ${ }^{\mathrm{a}}$. ed.): CRV, 2014, p. 51-67.

Costa, F. A. (2013). O potencial transformador das TIC e a formação de professores e educadores. In: Almeida, M. E. B., Dias, P., \& Silva, B. D. (Org.). Cenários de inovação para educação na sociedade digital. São Paulo: Loyola, p. 47-74.

Freire, P. (1996). Pedagogia da autonomia: saberes necessários à prática educativa. (34ª ed.): Paz e Terra.

Fialho, L. M. F., \& Nascimento, K. A. S. do. A Experiência de Indexação da Revista Educação \& Formação. In: ABEC Meeting Live, 2020. Anais... São Paulo: Associação Brasileira de Editores Científicos, 2020.

Hodges, C., Moore, S., Lockee, B., Trust, T., \& Bond, A. (2020). The Difference Between Emergency Remote Teaching and Online Learning. March 27. https://er.educause.edu/articles/2020/3/the-difference-between-emergency-remote-teaching-and-online-learning

Lagarto, J. R., Inovação, T. I. C., e sala de aula. In: Cavalheiri, A., Engerroff, S. N., \& Silva, J. C. (Org.). As novas tecnologias e os desafios para uma educação humanizadora. Santa Maria: Biblos, 2013, p. 133-158.

Moodle. Philosophy. docs.moodle.org/en/Philosophy.. S.d.Moodle. The Pedagogy. Moodle http://docs.moodle.org/en/Pedagogy.

Moran, J. M. Contribuições para uma pedagogia de educação on-line. In: Silva, M.(or.) Educação on-line: teorias, práticas, legislação e formação corporativa. São Paulo. Loyola, 2003. http://www.eca.usp.brlproflmoranlcontrib.htm

Moore, M. G., \& Kearsley, G. Educação a distância: uma visão integrada, 1. ed. São Paulo: Thomson Learning, 2007Oliveira. C. C., Costa, J. W., \& Moreira, M. Ambientes Informatizados de Aprendizagem. Papirus, 2001.

Oliveira, M. S. A história da educação a distância e contexto atual. In: Coelho, F. J. F., \& Velloso, A. Educação a distância: história, personagens e contextos, (1 $1^{\mathrm{a}}$. ed.): CRV, 2014, p. 15-35.

Organização Mundial da Saúde. Manual do AnthroPlus para computadores pessoais: Software para avaliação do crescimento de crianças e adolescentes no mundo. Genebra: Organização Mundial da Saúde; 2011. De: http://www.who.int/childgrowth/software/en/

Passarelli, B., Junqueira, A. H., \& Angeluci, A. C. B. Os nativos digitais no Brasil e seus comportamentos diante das telas. Matrizes. São Paulo, 8(1), 159178, jan./jun. 2014.

Pereira, A. T. C., Schmitt, V., \& Dias, M. R. Á. C. Ambientes virtuais de aprendizagem. In: Pereira, A. T. AVA - ambientes virtuais de aprendizagem em diferentes contextos, (1 ${ }^{\mathrm{a}}$. ed.): Ciência Moderna, 2007, p. 2-22.

Pessoa, R. (2020). Os desafios dos docentes em tempos de pandemia e de novas tecnologias de ensino. Ascom Adufg- Sindicato - noticias. https://www.adufg.org.br/noticias/2-noticias/8696-artigo-os-desafios-dos-docentes-em-tempos-de-pandemia-e-de-novas-tecnologias-de-ensino". Autores, coloquem em itálico "scom Adufg- Sindicato - noticias

Ribeir, R. S. Educação on-line,Moodle e suas possibilidades de educacionais:webartigos,2010

Sampaio, R. M. Práticas de ensino e letramentos em tempos de pandemia da COVID-19. Research, Society and Development, [S. 1.], 9(7), e519974430, 2020. 10.33448/rsd-v9i7.4430. https://www.rsdjournal.org/index.php/rsd/article/view/4430

Scheneider, D., Silva, K. K. A., \& Behar, P. A. Competência dos atores da educação a distância. In: Behar, P. A. Competência em educação a distância, (1ª . ed.): Penso, 2013, p. 152-173.

Valente, J. A., \& Almeida, M. E. B. Políticas de tecnologia na educação no Brasil: visão histórica e lições aprendidas. [Brazilian technology policies in education: History and lessons learned]. Arquivos Analíticos de Políticas Educativas [Education Policy Analysis Archives], 28(94). http://epaa.asu.edu/ojs .

Valente, J. A., Moran, J. M., \& Arantes, V. A. (Org.). Educação a distância: pontos e contrapontos. Summus, 2011. 